\title{
Trends and patterns in homicides in Italy: A 34-year descriptive study
}

\author{
Monica Vichi ${ }^{\mathrm{a}}$, Silvia Ghirini ${ }^{\mathrm{b}}$, Paolo Roma ${ }^{\mathrm{c}, *}$, Gabriele Mandarelli $^{\mathrm{d}}$, Maurizio Pompilie, \\ Stefano Ferracutic \\ a Statistical Service, Istituto Superiore di Sanità, viale Regina Elena, 299 - 00161 Roma, Italy \\ ${ }^{\mathrm{b}}$ National Center on Addictions and Doping, Istituto Superiore di Sanità, viale Regina Elena, 299 - 00161 Roma, Italy \\ ${ }^{\mathrm{c}}$ Department of Human Neurosciences, Sapienza, University of Rome, P.le A. Moro 5, 00185, Roma, Italy \\ d University of Bari Aldo Moro, Interdisciplinary Department of Medicine, Section of Criminology and Forensic Psychiatry, Bari, Italy \\ e Dept. of Neurosciences, Mental Health and Sensory Organs, Suicide Prevention Center, Sant'Andrea Hospital, Sapienza University of Rome, Via di Grottarossa, \\ 1035, 00189 Rome, Italy
}

\section{A R T I C L E I N F O}

\section{Article history:}

Received 2 August 2019

Received in revised form 22 November 2019

Accepted 24 December 2019

Available online 3 January 2020

\section{Keywords:}

Homicide

Violence

Epidemiology

Mafia

Italy

\begin{abstract}
A B S T R A C T
Aims: We aimed at analyzing homicide trends and patterns in Italy over the period 1980-2014.

Methods: We collected data from the Italian Mortality Database (Italian National Institute of Statistics), for the study period. Temporal trends were analyzed using joinpoint regression analysis, with estimated annual percentage change computed for each detected trend. The possible effect of the mafia subculture was examined using an indicator of mafia social penetration. Differences between age classes, genders, geographical regions, and homicide methods were also analyzed.

Results: The analyses showed an overall reduction in homicides during the study period, including a reduction in homicides by firearm. Further, we found significant differences between homicides involving male and female victims. A peak in male homicides, observed in the early 1990s, was significantly associated with mafia penetration.

Conclusions: The overall reduction in homicides can be interpreted as an expression of a "civilizing process."
\end{abstract}

(c) 2020 Elsevier B.V. All rights reserved.

\section{Introduction}

Intentional homicide is an unlawful act of death that is purposefully inflicted [1]. It is among the leading causes of death in many nations and it can also be considered a public health problem, as it impacts the mental health of the relational network and social environment of both the victim and the offender [2-6]. Social factors such as poverty, inequality, education, impunity, corruption, mental health, and alcohol and drug consumption have been found to be associated with homicide rates [7-9].

In most developed countries, homicide rates are stable or declining [1]. Currently, Italy ranks 149 out of 173 countries worldwide for the rate of this crime [1]. The global average homicide rate in 2012 was reported to be 6.2 per 100,000 persons, with the highest rates recorded in Southern Africa and Central America (16.3 and 12.5 homicides per 100,000 persons, respectively) and a considerably lower rate recorded in Europe (3.0 homicides per 100,000 persons). A possible explanation for the

\footnotetext{
* Corresponding author.

E-mail address: paolo.roma@uniroma1.it (P. Roma).
}

observed decline in homicides may be provided by Elias's (1988) theory of the "civilizing process." Elias predicted long-term declines in the rate of violent crimes in industrialized Western European countries (e.g., France and Germany) due to two related processes: (a) the state's increasing monopoly on the legitimate use of violence and (b) the rise of complex social and economic configurations, which were thought to trigger a cultural change towards a more rational way of living, characterized by higher selfcontrol and lower impulsivity.

The international literature on homicide outlines trends and features of this crime, as well as its victims (with respect to, e.g., age, gender, etc.). Concerning the latter, research has consistently found that the rate of homicide victimization is higher for males than for females [10,11]; this has also been confirmed in Italy, where men have been found to be five times more likely than women to be the victim of this crime [12].

Some authors have hypothesized that this gender difference in the homicide victimization rate could be ascribed to biological differences: males tend to be more aggressive and more inclined toward violence than women-who, for example, tend to require greater provocation to react with violence [13]. The fact that those who are more aggressive are also more likely to be on the receiving 
end of aggression [14] could explain why men have a higher rate of homicide victimization. However, some authors have suggested that this gender difference might have a cultural explanation rooted in gender differences in occupation and daily activities. For instance, opportunity models of homicide victimization (e.g., the routine activity approach [15]) imply that the homicide rate is a function of opportunities for victimization [16]. Since men have traditionally comprised the main portion of the labor force, it is safe to assume that they would have encountered more victimization opportunities.

Moreover, 70 years ago, Verkko [17] proposed that the proportion of female homicide victims may be higher when the overall homicide rate is low (and vice versa), thus hypothesizing that there is a basic number of victimized women that cannot be reduced. The accuracy of "Verkko's law" was subsequently confirmed in several countries, including France [18] and England/Wales [19].

Research has found that the peak age range for homicide victimization is 25-34 years old for both genders, and it has also found that the homicide rate tends to decrease with the victim's older age; however, the degree of this decline varies over time and across nations [20-22]. In Italy, a similar age range for the peak age for homicide victimization was found [12], though the pattern emerged more clearly for men than for women. This result could also be explained by opportunity models of homicide victimization, as suggested by Gartner [16]: "the younger a population and the more widely dispersed its activities, the less effective are social controls and the more extensive are opportunities for homicide" (p. 95).

A particular age bracket for homicide victimization (0-14 years), which we define as "child homicide," shows some peculiarities when compared to adult homicide. Since the 1960s, child homicide rates have declined in many Western countries. Pritchard [23] reported declines of $20-100 \%$ in various European countries between the 1970s and 2000s. Several other studies have also reported decreased levels of child homicide, including studies from the US [24,25], Hungary [26], Finland [27], and Sweden [28]. However, gender differences in child homicide are not consistent throughout the literature. In fact, some studies have indicated that male children are more likely to die by homicide [29-31], whereas others suggest that female children are more likely to be homicide victims [32,33]. In contrast to the findings for adult homicide, no gender-based trend has been observed for child homicide; the latter, in fact, seems mostly influenced by a mosaic of external and contextual factors, including child welfare conditions, gun policies, the dynamics of the drug market, abortion policies, and the availability of services for victims of domestic abuse [25].

Violence, sometimes in the form of homicide, is a dominant feature of organized crime [34,35]. In southern Italy, mafia-type criminal organizations [36], which are differently named according to the territory (e.g., mafia, camorra, 'ndrangheta, sacra corona unita), have existed for many decades. The literature on organized crime and its impact on homicide rates is somewhat scarce and often uses the term "organized crime" in an ambiguous way (e.g., including gang-related crimes). Preti and Miotto [12] indicated that, between $1980-1994$, “34\% of total death by homicide in Italy is rated as mafia- related" (p. 237). Furthermore, an analysis conducted by the Italian National Institute of Statistics [37] highlighted that, in the period 1983-2017, 6663 homicides could be attributed to mafia-type criminal organizations. It is worth noting that, in this timeframe, 95.5\% of the homicides were committed in territories that have historically been connected with organized crime (i.e., Sicilia, Campania, Calabria, Puglia). These data reveal a high level of subnational variation across regions: in the 1990s, for example, the homicide rate in Reggio Calabria (one of the largest cities in Calabria, historically characterized by a strong 'ndrangheta presence) peaked at 36 per 100,000 inhabitants [38].

To provide further insight into Italian homicide trends relating to these variables, we analyzed homicide data over a 34-year period (1980-2014) in Italy. Specifically, we investigated the following: adult homicide victims, by gender and age; children victims of homicide, by gender; murder methods; and the relationship between homicide and the presence of organized crime. Our hypotheses were as follows:

1. Over the study period, the number of adult victims would decrease while the relationship between women and men would grow in favor of women.

2. Over the study period, the number of victims would decrease in both genders.

3. In places where organized crime was more socially rooted, homicide would have been facilitated during the study period due to the implicit transmission of violence and aggression towards citizens-regardless of the motivating factor for the homicide. For this investigation, the Mafia Presence Index and distribution of homicides by geographical area were used.

Further insight into the above areas could inform policymakers working on homicide prevention. Moreover, knowledge of the invariants and differences in homicides between men and women in a public health perspective could provide new lines of action for reducing violence relating to assault [39].

\section{Method}

\subsection{Data collection}

To examine gender differences in homicide victimization trends and patterns, we analyzed data from the Italian Mortality Database collected by the Italian National Institute of Statistics (ISTAT) and processed by the Statistics Unit of the National Institute of Health (Istituto Superiore di Sanità). The analyses focused on the most recent periods for which data were available (i.e., 1980-2014). ISTAT collects all death certificates of Italian residents and codes the initial cause of death according to the International Classification of Diseases (ICD 9th revision [ICD-9], from 1980 to 2002; ICD 10th revision [ICD-10], from 2003 to 2014). Deaths due to homicide are coded as "External Causes," labeled E960-E969 (ICD-9) and X85-Y09, Y87.1 (ICD-10). Method of murder is grouped into one of five categories (Table 1 ).

Table 1

Murder method codes: ICD-9 and ICD-10.

\begin{tabular}{|c|c|c|}
\hline Method & ICD-9 & ICD-10 \\
\hline Physical force, strangulation, maltreatment & E960, E963, E967, E968.4 & X91, Y04-Y07 \\
\hline Firearm & E965.0-E965.4 & X93-X95 \\
\hline Sharp or blunt object (e.g. cutting weapon) & E966, E968.2 & X99, Y00 \\
\hline Other & $\begin{array}{l}\text { E961, E962, E964, E965.5-E965.9, } \\
\text { E968.0, E968.1, E968.3, E968.8 }\end{array}$ & $\begin{array}{l}\text { X85-X90, X92, X96-X98, } \\
\text { Y01-Y03, Y08 }\end{array}$ \\
\hline Unknown and late effect & E968.9, E969 & Y09, Y87.1 \\
\hline OVERALL & E960-E969 & X85-Y09, Y87.1 \\
\hline
\end{tabular}


In 1980, the Italian population was approximately 56 million; in 2018, this number had increased to approximately 59 million. Italy is currently divided into 20 administrative regions and 107 subregional administrative provinces, which are grouped into four geographical areas: North-West (NW), North-East (NE), Center (C), and South and Islands (SI).

\subsection{Mafia presence index}

To evaluate mafia presence, we used the Mafia Presence Index (MPI), as compiled by the Research Centre on Transnational Crime (http://www.transcrime.it/en/about/). The MPI draws on direct and indirect indicators, including charges filed against persons for mafia associations, the dissolution of city councils due to mafia infiltration, and assets confiscated from organized crime [40]. For the present study, Italian provinces were grouped according to the five MPI levels: very low, low, medium, high, and very high (see supplementary materials).

\subsection{Statistical analysis}

Age-adjusted rates per 100,000 individuals per year were calculated separately by gender using the direct standardization method with the 2011 Italian Census population as reference. The age-adjusted rates were calculated according to age $(0-9,10-14$, 15-24, 25-44, 45-64, and 65+ years), geographical area (NW, NE, C, SI), MPI, and murder method (see Table 1). Unless stated otherwise, the analyses refer to Italian residents aged 15 years and older. The homicide trend of children aged 0-14 years was separately analyzed on a 2-year base.

Temporal trends were analyzed for the period 1980-2014 using joinpoint regression analysis, which enabled us to identify the calendar years in which the temporal trend changed significantly. An estimated annual percentage change (APC) was computed for each detected trend by fitting a regression line to the natural logarithm of the rates, using calendar years as the regressor variable. The joinpoint analysis was applied to the age-adjusted rates (and their standard errors). Models were estimated separately for men and women, for age classes, for murder method, for geographical region, and for MPI group. APC was considered statistically significantly different from 0 if the $p$-value for the two-sided $t$-test was less than 0.05. Detailed results of the joinpoint analysis, including the $95 \%$ confidence intervals for APC, are reported in the supplementary tables.

The analyses were performed using the commercial statistical programs IBM-SPSS 25 (IBM-SPSS Corp., Armonk, NY) and SAS 9.4 (SAS Institute, Cary, NC). Rates were computed with the integrated system of programs called PATED (Procedure for the Spatial Analysis of Descriptive Epidemiology, version 4.3; [41]). Joinpoint regression was performed by the Joinpoint Regression Program (version 4.6) by the Statistical Research and Applications Branch, National Cancer Institute.

\section{Results}

\subsection{Trends in homicide victimization, by gender}

Fig. 1 shows the trends in homicide victimization from 1980 to 2014 , by gender. For men, the rate of homicide victimization increased in the early 1980s then reduced until the mid-1980s. In the second half of the 1980s, a sharp increase lasted until the beginning of the 1990 s, reaching a maximum of 5.49 per 100,000 persons in 1991 (APC 1986-1990: +24.1, $p<0.01$; Tables A1 and A3, supplementary materials). The rate then decreased quickly until 1996 (APC 1991-1996: $-14.9, p<0.01$ ), then decreased at a slower rate until 2014 (APC 1996-2014: $-5.3, p<0.01$ ). In 2014, the rate of

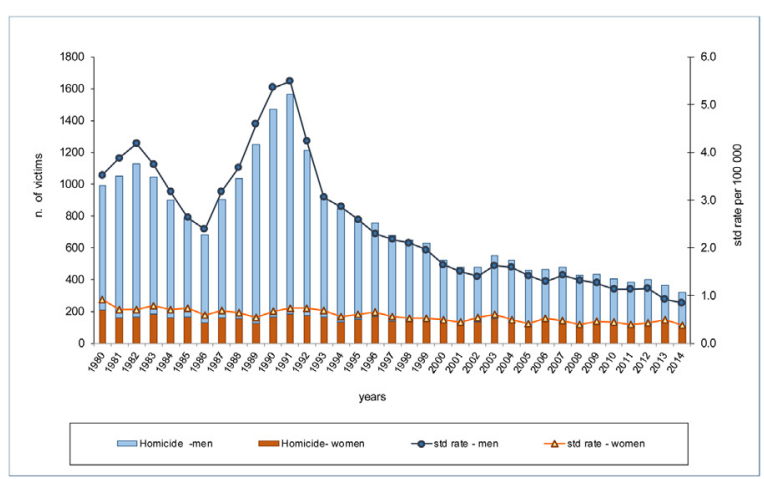

Fig. 1. Male and female homicide victims. Number of deaths and standardized mortality rate (per 100,000 inhabitants aged 15 years and older). Italy, 1980-2014.

male victimization reached its minimum of 0.85 per 100,000 persons. For women, the rate decreased slowly and continuously throughout the entire 34-year period, beginning at 0.92 per 100,000 persons in 1980 and ending at 0.38 per 100,000 persons in 2014 (APC 1980-2014: - 1.9, $p<0.01$; Tables A2 and A4, supplementary materials). The male to female homicide ratio declined from a maximum of 8.5 in 1989 to 2.2 in 2014 .

\subsection{Trends in homicide victimization, by gender and age}

The homicide mortality rate among men aged 25-44 years proved consistently higher than the corresponding rate in all other age groups; men aged 65 years and older showed the lowest homicide mortality rate (Fig. 2a). A reduction in the homicide mortality rate among men was observed from the beginning of the 1990 s, and was more accentuated among the younger age groups. The highest decrease was observed among men aged $15-24$ years

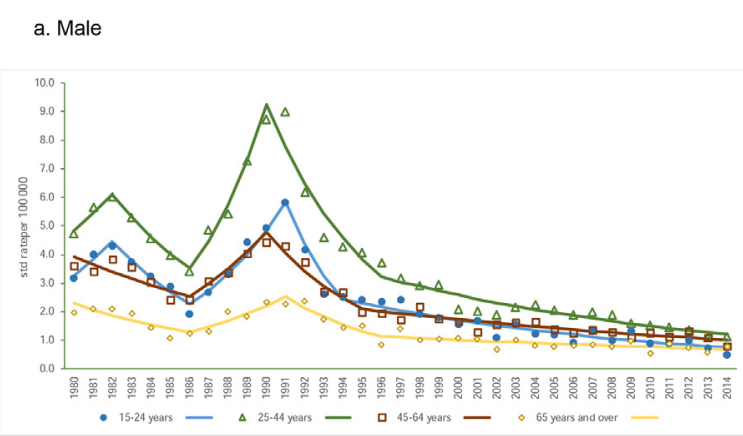

b. Female

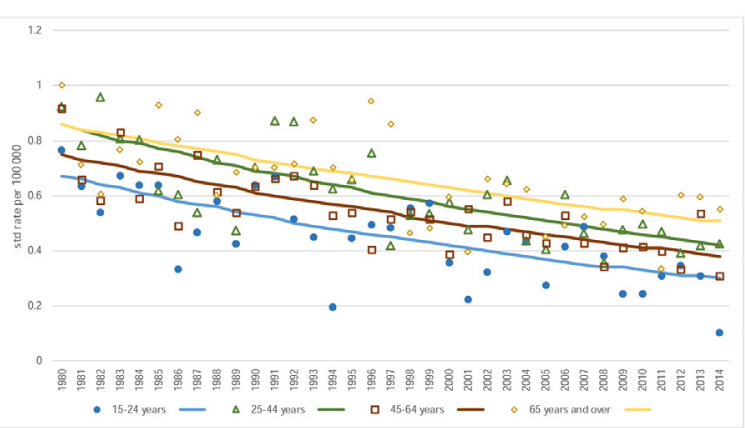

Fig. 2. a. Male homicide victims, by age. Standardized rates (symbols) and estimated trends (straight lines). Italy, 1980-2014. b. Female homicide victims, by age. Standardized rates (symbols) and estimated trends (straight lines). Italy, 1980-2014. 
(APC 1991-1994: -25.3, $p<0.01$; APC 1994-2014: $-5.8, p<0.01$; Tables $A 1$ and $A 3$, supplementary materials), with the rate decreasing from a value of 5.82 per 100,000 persons in 1991 to 0.49 per 100,000 persons in 2014 . Important reductions were also recorded for the age ranges of 25-44 years (APC 1990-1996: -16.1, $p<0.01$; APC 1996-2014: $-5.3, p<0.01$ ) and $45-64$ years (APC 1990-1995: $-15.3, p<0.01$; APC 1995-2014: $-3.8, p<0.01)$. A lower decrease was observed for the elderly, especially in more recent years (APC 1991-1996: -14.9, $p<0.01$; APC 1996-2014: $-2.7, p<0.01)$.

Women (Fig. 2b) aged 65 and older showed the highest homicide mortality rate, at a value of 1.0 in 1980 , decreasing to 0.31 in 2014 (APC 1980-2014: -1.5, $p<0.01$; Tables A2 and A4, supplementary materials). The decreasing trend in women was greatest among the younger age groups, with the highest decrease observed among women aged 15-24 years (APC 1980-2014: -2.4, $p<0.01$ ), followed by those aged 25-44 and 45-64 (APC 19802014: -2.1 and -2.0 , respectively, $p<0.01$ ).

\subsection{Trends in child homicide}

The standardized rate of homicide involving children (aged $0-$ 14 years) showed a decreasing trend over the study period (ACP 1981-2014: $-2.7 ; p<0.01$; Fig. 3; Tables A5 and A6, supplementary material). For boys, there was a statistically insignificant peak in the biennia 1989-1990, when the rate reached a maximum of 0.40 per 100,000 persons. For girls, the homicide rate was lower than that of males until 1993-1994, when the trend became similar between genders. A more pronounced decrease began in 19931994, and was more easily observed among children aged 10-14 years than those aged $0-9$ years.

\subsection{Trends in geographical region}

The SI region showed a variable trend in male homicide rates (Fig. 4a). In this region, male homicide peaked at the beginning of the 1990s and sharply decreased in the period of 1990-1995; a smaller decrease occurred thereafter (APC 1990-1996: -16.3, $p<0.01$; APC 1996-2014: $-5.8, p<0.01$; Tables A7 and A9, supplementary materials). A similar trend was recorded in the regions of the NW (APC 1990-1994: $-17.2, p<0.01$; APC 19942014: $-2.5, p<0.01$ ) and C (APC 1990-2014: $-11.6, p<0.01$; APC 1995-2014: $-1.6, p<0.01)$, where the base homicide rates were lower. In the NE region, the decrease in homicide rates was statistically significant only for the period 1995-2014 (APC: -2.0 , $p<0.01$ ).

As regards women, higher homicide mortality rates were recorded in the SI region compared to all other Italian areas until the mid-2000s (Fig. 4b). In the period 1992-2014, the SI region

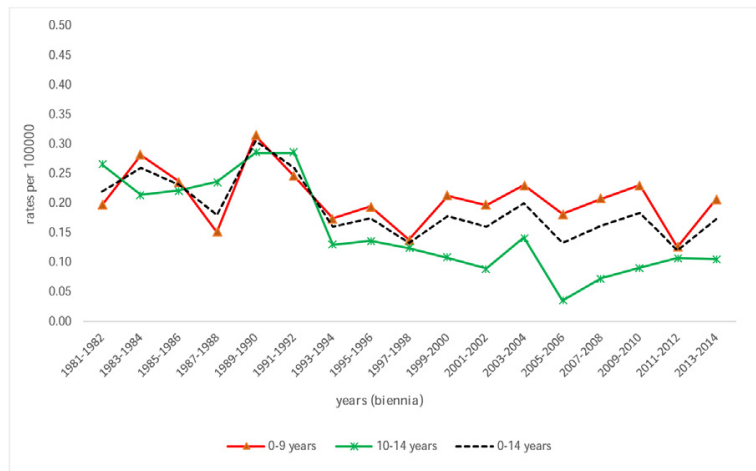

Fig. 3. Infant (aged 0-14 years) homicide victims, by age. Age-adjusted rates. Italy, $1981 / 1982-2013 / 2014$.
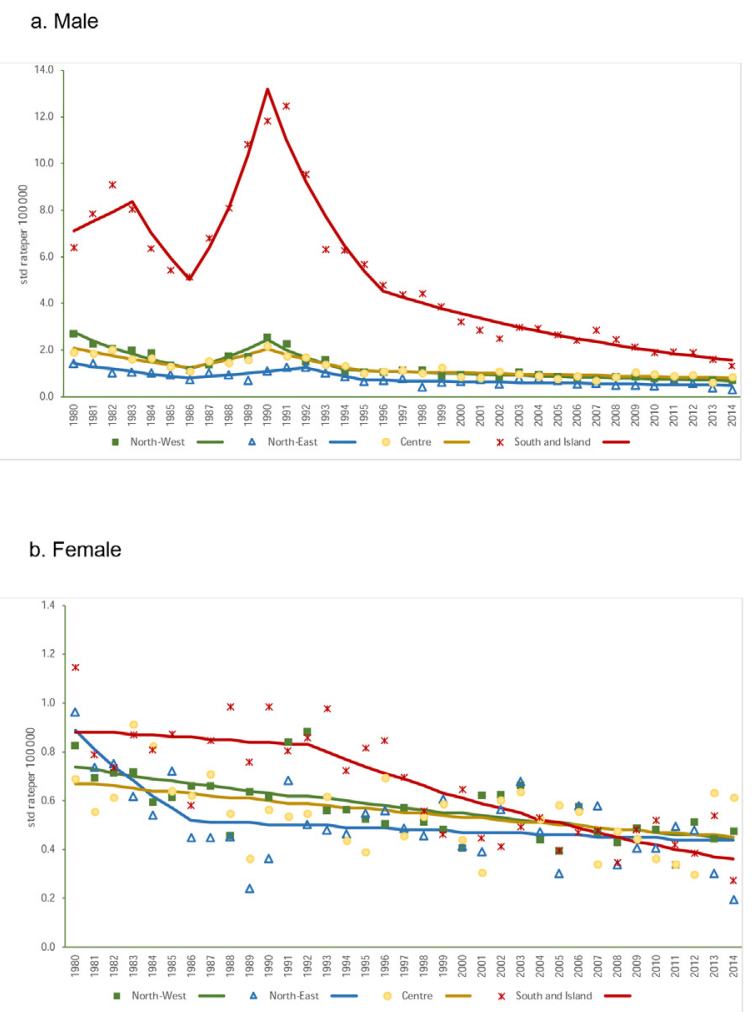

Fig. 4. a. Male homicide victims, by geographical region. Standardized rates (symbols) and estimated trends (straight lines). Italy, 1980-2014. b. Female homicide victims, by geographical region. Standardized rates (symbols) and estimated trends (straight lines). Italy, 1980-2014.

showed the greatest reduction (APC: $-3.7, p<0.01$; Tables A8 and A10, supplementary materials) and, in the last year of observation, the highest homicide rates for women were observed in the regions of the $C(0.61$ per 100,000 inhabitants $)$ and NW ( 0.47 per 100,000 persons).

\subsection{Trends in the MPI}

The analysis of homicides by MPI highlighted a higher rate of homicides in areas with a higher mafia presence, although a distinct pattern emerged for men and women (Fig. 5a, 5b). In the analysis relating to men, a peak in homicides emerged in the period 1989-1991, and this peak was greatest in areas with high MPI; no such peak was observed among women. In the following years, the mortality rate for male homicide showed a sharp decrease, especially in very high MPI areas (APC 1991-1994: -24.8, $p<0.01$; APC 1994-2014: $-6.6, p<0.01$; Tables A11 and A13, supplementary materials). Starting in the early 1990s, relevant decreases were also recorded in high MPI (APC 1990-1996: -14.7, $p<0.01$; APC 1996-2014: $-4.3, p<0.01)$ and medium MPI areas (APC 1991-1995: -19.6, $p<0.01$; APC 1995-2014: $-3.5, p<0.01$ ). A less pronounced decrease was recorded from the mid-1990s onwards for very low MPI areas (APC 1993-2014: $-3.5, p<0.01$ ), while the decrease was non-significant for low MPI areas. In the last year of observation, the mortality rate in very high MPI areas was still more than double that of very low MPI areas (1.34 per 100,000 vs. 0.56 per 100,000 persons).

For women (Fig. 5b), we observed comparatively less variability in the homicide rate by MPI. There was a significant downward trend over the period 1980-2014 in areas of very high MPI (APC 1980-2014: $-2.1, p<0.01$; Tables A12 and A14, supplementary materials), high MPI (APC 1980-2014: $-1.9, p<0.01$ ), and low MPI 

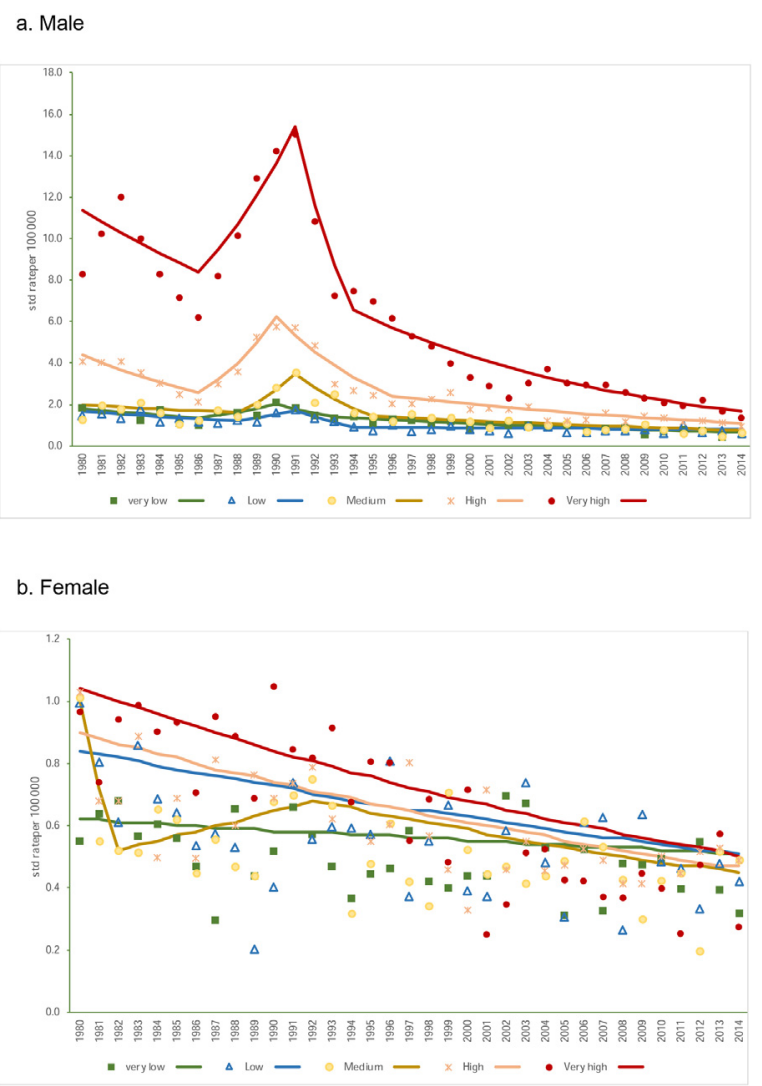

Fig. 5. a. Male homicide victims, by MPI. Standardized rates (symbols) and estimated trends (straight lines). Italy, 1980-2014. b. Female homicide victims, by MPI. Standardized rates (symbols) and estimated trends (straight lines). Italy, 19802014.

(APC 1980-2014: $-1.5, p<0.01$ ). The decrease in medium MPI areas was significant for the period 1992-2014 (APC: $-1.9, p<0.01$ ) but it was not significant in very low MPI areas. At the beginning of the period, we found a significantly higher mortality rate in very high MPI areas (in 1980: 0.97 per 100,000 inhabitants) compared to very low MPI areas (in 1980: 0.55 per 100,000 persons). However, at the end of the period, the variability was greatly reducedand the mortality rate for women was even higher in very low MPI areas ( 0.32 per 100,000 persons) compared to very high MPI areas ( 0.27 per 100,000 persons).

\subsection{Trends in murder method}

Throughout the study period, the most frequently used murder method for male victims was a firearm (Fig. 6a). A maximum of 4.57 murders by firearm per 100,000 persons was reached in 1991, followed by a significant decrease (APC 1990-1995: -18.0, $p<0.01$; APC 1995-2014: $-6.5, p<0.01$; Tables A15 and A17, supplementary materials). From the 1990 s onward, a significant reduction was also observed for male victims killed by a cutting weapon (APC 1990-2014: -2.3, p<0.01); from 1987 to 2014 no significant reductions were observed for homicide by physical force.

Among female victims, there was a significant decrease in homicides by all methods apart from "other methods," throughout the study period (Fig. 6b). The greatest reduction was observed for homicide by firearm (APC 1980-2014: $-3.1, p<0.01$; Tables A16 and $A 18$, supplementary materials), followed by homicide by physical force (APC 1980-2014: $-1.3, p<0.01$ ). A smaller reduction was also observed for homicide by cutting weapon (APC 1980-
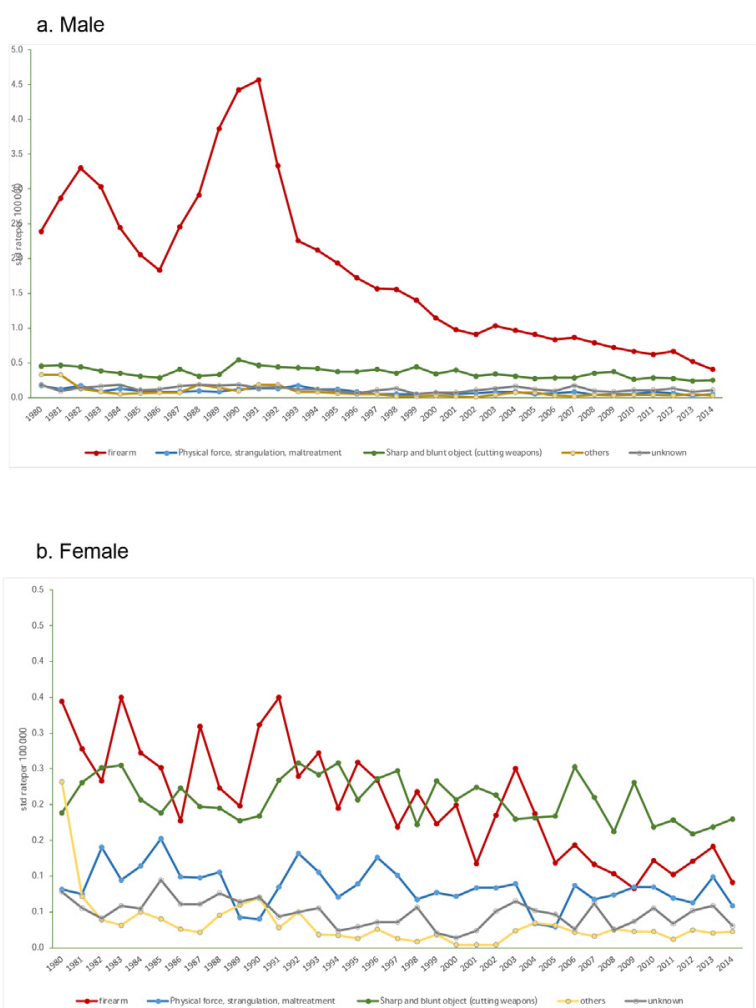

Fig. 6. a. Male homicide victims, by murder method. Standardized rates. Italy, 1980-2014. b. Female homicide victims, by murder method. Standardized rates. Italy 1980-2014.

2014: $-0.6, p<0.01)$. Firearm and cutting weapon were the two most frequently used murder methods for female victims over the study period, with homicide by cutting weapon becoming the primary method after 2005.

Exploring the temporal trend of firearm homicides stratified by MPI, a clear figure emerged for male victims (Fig. 7a) in high and very high MPI areas, where there was a very important increase from 1985 to 1990 (APC 1986-1990: $+20.8, p<0.01$ in very high MPI areas; +30.6, $p<0.01$ in high MPI areas; Tables 19 and 20, supplementary materials), followed by a sharp decrease in subsequent years. At the beginning of ' 90 s, the firearm homicide rate peaked at 11.81 per 100,000 persons in very high MPI areas and 4.36 in high MPI areas. Also, in areas with an MPI other than high or very high, a reduced firearm homicide rate was observed among men, starting in 1990.

For women (Fig. 7b), we observed a continuous reduction from 1980 to 2014 in all areas except for very high MPI areas, for which the rate started to decrease in 1991 (Tables A20 and A22, supplementary materials).

\section{Discussion}

The 34-year period of homicide victim data showed a significant decrease in the homicide rate for both genders, although different trends emerged. Women showed a linear decrease in all age groups, while men showed increased victimization until the beginning of the 1990s, followed by a rapid decrease, particularly in the age group of 25-44 years. In the last year of observation, male and female homicide rates were 0.85 and 0.38 per 100,000 persons, respectively.

As expected, the ratio of male to female homicide progressively decreased, from a maximum of 8.5 in 1989 to a minimum of 2.2 in 2014. Despite the different gender trends, there was a general 

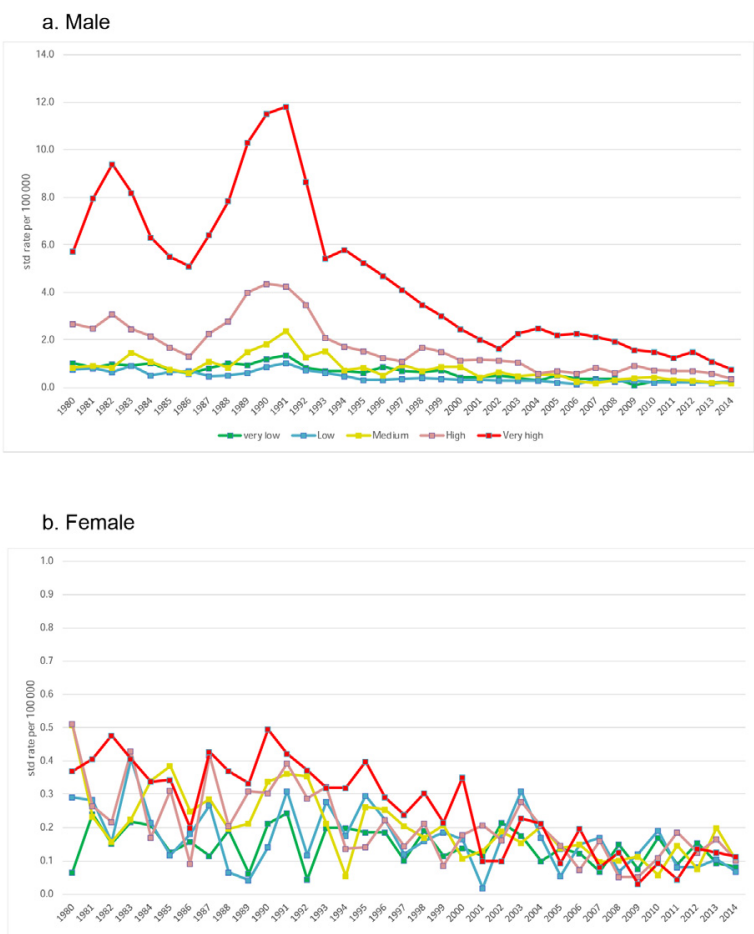

Fig. 7. a. Male firearm homicide victims, by MPI. Standardized rates. Italy, 19802014. b. Female firearm homicide victims, by MPI. Standardized rates. Italy, 19802014.

reduction in the incidence of homicide, in line with data from other countries. The 2014 rate represents the lowest victimization rate ever observed in Italy, still below the figure reached in the period of 1962-1971 [42].

From the $19^{\text {th }}$ century to the first half of the $20^{\text {th }}$ century, Italy's homicide rate was consistently higher than those recorded in other Western countries [43]. In particular, Italian data from the period 1864-2009 [44] demonstrated four peaks in the incidence of this crime: 1891-1893, which was a period of intense social turmoil; 1919-1920, which were years dominated by a radical left-wing social struggle before the rise of fascism; 1945-1947, which was the post-WWII period; and 1991, which was when the homicide rate reached its highest peak since 1948. This significant increase might be interpreted in light of the fact that, between the 1980s and 1990s, Italy witnessed a dramatic escalation of conflict with the mafia, culminating in the murder of two judges (Falcone and Borsellino) and the rise to power of the so-called "new mafia" in the second half of the 1990s $[45,46]$. In this context, the homicide rate may reflect a resource competition between criminal groups. During the latter peak (1995-2000), specifically, many homicides were committed in low MPI areas, in both Italy and other European countries [9]. Regarding Italy, this quinquennium was also characterized by conflict relating to control over the drug market, which involved murders throughout the Italian peninsula [37]. Outside Italy, similar peaks in the homicide rate were observed in Russia after the collapse of the USSR, when gang wars for territorial control (involving bombings, assassinations, drive-by shootings, etc.) became widespread [47,48]. Moreover, in European countries, a homicide peak in the first half of the 1990s has been ascribed to conflict over the control of illegal markets, the consolidation of problematic neighborhoods, and an increase in the recording of violent offences by the police [49].

Our analyses of the homicide data by geographical region and MPI showed that, in Italy, the homicide rates proved highest in areas characterized by high MPI. Accordingly, we observed a decrease in the homicide rate in areas with high MPI, such as the SI region. This led to reduced geographical variability in later years and to convergence of the homicide rates in various Italian regions: in particular, the homicide rate ratio of very high MPI to very low MPI areas more than halved during the period 1980-2014 for both genders (from 4.6 to 2.4 for men and from 1.8 to 0.8 for women). This result is in line with the results of previous studies [37] highlighting the remarkable difference in the mafia-related homicide rate between one of the bloodiest periods (19881992)-when more than one-third of the roughly 8000 homicides were mafia-related-and more recent times (2013-2017), when mafia-related homicides comprised $9.1 \%$ of all homicides.

From 1990-2014, murders committed by firearm showed the greatest reduction compared to murders committed by other killing methods, for both genders; at the end of the observation period, homicide by firearm reached a level akin to death by other means. As murder by firearm is the most common method used by criminal groups, the observed reduction in homicide by this method is likely related to the reduction of mafia-related murders during the same time period (see Fig. 7a and b and Tables A19A22). The analysis showed that, indeed, this decrease was particularly evident for men in regions with medium to very high MPI. Nonetheless, murder by firearm is still the primary method of homicide for men. This result is in line with the theory that the homicide weapon, among other factors, is dictated by the offender-victim differential in physical strength [50,51]; in other words, when the homicide victim is male, the method used is often one that does not require physical strength (e.g., a firearm), as opposed to one that is physically demanding. For women, use of a cutting weapon recently surpassed firearm as the primary method of homicide; this is possibly due to the fact that women homicides tend to be intrafamilial and performed with commonly available tools.

Regarding child homicides in Italy, the rate decreased substantially over the 34-year study period, in line with trends in other Western countries $[23,25,26,27,28]$. The reasons for this may relate to social aptitude changes, as described by Lehti et al. [27]. Specifically, in recent years, the family structure has become more fluid (i.e., the rate of family breakdown more than tripled in the period 1980-014; [42]), compared to the 1980s. A widespread network of social and health services is well represented in Italy, and significant changes in gender roles have taken place. The increasing availability of social assistance and mental health services in Italy since the 1980s might explain both the motivations and the opportunities for child homicides, as also reported by Rying [52] and Somander and Rammer [53].

Nevertheless, the reduction in the child homicide rate is lower than that observed for adult victims. It is possible that child homicide has closer ties with untreated mental illness or familiar murder-suicide. Also, the trend for male victims aged $10-14$ years is very similar to the trend for adult victims, indicating a tie with adult victimization. Moreover, it must be said that a proportion of child homicides in Italy can be explained by murder-suicides-a phenomenon that remains prevalent in the country $[54,55,56]$.

Before drawing conclusions, some limitations of the present study must be acknowledged. First, the study was descriptive; thus, future epidemiological studies should analyze the risk factors related to homicide more deeply. Moreover, as the analysis was based on victims' data, it does not provide insight into criminal motivations. This is particularly true for the infant and child homicides, as well as the differences that emerged between adult groups. Third, the study used secondary data analysis (i.e., it was an archival study); therefore, it was not possible to detect changes over time relating to methods, detection accuracy, classification, and identification. 


\section{Conclusion}

Our analysis of trends and patterns in homicides in Italy over a 34-year period showed an overall decrease in homicide rates that can be interpreted as an expression of a "civilizing" process [57]. Increases in medical knowledge and surgical techniques have reduced the lethality of aggressive acts [58,59], thus reducing the occurrence of violent deaths. Evaluating the data in a broader perspective and considering the victims of mafia violence, we consider that the reduction in victimization rates can be mainly ascribed to homicides related to organized crime activity. On this basis, it is possible to detect an increased proportion of so-called "interpersonal" murders, including those committed by intimate partners (e.g., feminicides; [9]), in the total set of homicides. In order to achieve a further reduction in the mortality rate due to murder, it is necessary to invest in not only crime-suppression initiatives, but also-and with a view to public health-prevention policies aimed at reducing inequalities (including gender inequalities), increasing education, and facilitating employment. Of particular importance are policies directed at young people, aiming at preventing school drop-outs and increasing educational provisions, both inside and outside the school environment. Education is a key element in the reduction of violence, as it increases resilience to crime and victimization and provides employment opportunities [9]. Finally, because violence against children tends to relate to perinatal conditions, investment should be made in programs designed to prevent psychic distress in the perinatal period [60].

\section{Financial support}

This research received no specific grant from any funding agency in the commercial or not-for-profit sectors.

\section{CRediT authorship contribution statement}

Monica Vichi: Writing - review \& editing, Data curation, Formal analysis. Silvia Ghirini: Writing - review \& editing, Data curation, Formal analysis. Paolo Roma: Writing - original draft. Gabriele Mandarelli: Writing - review \& editing. Maurizio Pompili: Writing - review \& editing. Stefano Ferracuti: Conceptualization, Supervision.

\section{Declaration of Competing Interest}

None.

\section{Acknowledgements}

None.

\section{Appendix A. Supplementary data}

Supplementary material related to this article can be found, in the online version, at https://doi.org/10.1016/j.forsciint.2020.110141.

\section{References}

[1] United Nations Office on Drugs and Crime [UNODC], Global Study on Homicide 2013 (United Nations Publication, Sales No. 14.IV.1), (2014).

[2] E.G. Krug, L.L. Dahlberg, J.A. Mercy, A.B. Zwi, R. Lozano, World Report on Violence and Health, World Health Organization, Geneva, 2002.

[3] M. Vichi, S. Ghirini, Salute Mentale e dipendenze. Rapporto Osservasalute 2017. Stato di salute e qualità dell'assistenza nelle regioni italiane, Prex. Milano, 2018, pp. 251-277.

[4] D.J. Williams, P.D. Donnelly, Is violence a disease? Situating violence prevention in public health policy and practice, Public Health 128 (11) (2014) 960-967.
[5] World Health Organization [WHO], Global Plan of Action to Strengthen the Role of the Health System within a National Multisectoral Response to Address Interpersonal Violence, in Particular Against Women and Girls, and against Children, WHO, Geneva, 2016.

[6] A. Wolf, R. Gray, S. Fazel, Violence as a public health problem: an ecological study of 169 countries, Social Sci. Med. 104 (2014) 220-227.

[7] J. Gamlin, Violence and homicide in Mexico: a global health issue, Lancet 385 (9968) (2015) 605-606.

[8] A.J. Heinz, A. Beck, A. Meyer-Lindenberg, P. Sterzer, A. Heinz, Cognitive and neurobiological mechanisms of alcohol-related aggression, Nat. Rev. Neurosci. 12 (7) (2011) 400.

[9] United Nations Office on Drugs and Crime [UNODC], Global Study on Homicide (Booklets 1-6) Retrieved from https://www.unodc.org/unodc/en/data-andanalysis/global-study-on-homicide.html, UNODC, Vienna, 2019.

[10] R. Gartner, K. Baker, F.C. Pampel, Gender stratification and the gender gap in homicide victimization, Social Problems 37 (4) (1990) 593-612.

[11] A.L. Kellerman, J.A. Mercy, Men, women, and murder: gender-specific differences in rates of fatal violence and victimization, J. Trauma 33 (1) (1992) $1-2$.

[12] A. Preti, P. Miotto, Death by homicide in Italy, 1980-94: age and gender differences among victims, Med. Sci. Law 40 (3) (2000) 233-240.

[13] J. Fagan, A. Browne, Violence between spouses and intimates: physical aggression between women and men in intimate relationships, in: National Research Council (Ed.), Understanding and Preventing Violence, vol. 3: Social influences1994.

[14] C. Harris, B. Barraclough, Excess mortality of mental disorder, Br. J. Psychiatry 173 (1) (1998) 11-53.

[15] L.E. Cohen, M. Felson, Social change and crime rate trends: a routine activity approach, Am. Sociol. Rev. 44 (4) (1979) 588-608.

[16] R. Gartner, The victims of homicide: a temporal and cross-national comparison, Am. Sociol. Rev. 55 (1) (1990) 92-106.

[17] V.K.Verkko, Homicides and suicides in Finland and their dependence on national character, Scandinavian Studies in Sociology, G.E.C. Gads, Kobenhavn, 1951.

[18] L. Mucchielli (Ed.), La frénésie sécuritaire: retour à l'ordre et nouveau contrôle social, La découverte, Paris, 2013.

[19] K. Soothill, B. Francis, Homicide in England and Wales, Handbook of European Homicide Research, Springer, New York, NY, 2012, pp. 287-300.

[20] M. Daly, M. Wilson, Evolutionary social psychology and family homicide, Science 242 (4878) (1988) 519-524.

[21] F.C. Pampel, J.B. Williamson, Age patterns of suicide and homicide mortality rates in high-income nations, Social Forces 80 (1) (2001) 251-282.

[22] K. Tardiff, P.M. Marzuk, A.C. Leon, C.S. Hirsch, M. Stajic, L. Portera, N. Hartwell, Homicide in New York City: cocaine and firearms, JAMA 272 (1) (1994) 43-46.

[23] C. Pritchard, Family violence in Europe, child homicide and intimate partner violence, in: M. Liem, W. Pridemore (Eds.), Handbook of European Homicide Research, Springer, New York, NY, 2012, pp. 171-183.

[24] Bureau of Justice Statistics, Homicide Trends in the United States, (2010) Retrieved from http://bjs.ojp.usdoj.gov/content/homicide/children.cfm.

[25] D. Finkelhor, L. Jones, Why have child maltreatment and child victimization declined? J. Social Issues 62 (4) (2006) 685-716.

[26] K. Törő, S. Fehér, K. Farkas, G. Dunay, Homicides against infants, children and adolescents in Budapest (1960-2005), J. Forensic Legal Med. 17 (8) (2010) 407-411.

[27] M. Lehti, J. Kääriäinen, J. Kivivuori, The declining number of child homicides in Finland, 1960-2009, Homicide Stud. 16 (1) (2012) 3-22.

[28] S. Granath, Homicide in Sweden, in: M. Liem, W. Pridemore (Eds.), Handbook of European Homicide Research, Springer, New York, NY, 2012, pp, 405-419.

[29] K.K. Christoffel, Homicide in childhood: a public health problem in need of attention, Am. J. Public Health 74 (1) (1984) 68-70.

[30] J.M. Dawson, P.A. Langan, Murder in Families (Bureau of Justice Statistics Special Report), US Department of Justice, Office of Justice Programs, Bureau of Justice Statistics, Washington, DC, 1994.

[31] L. Margolin, Fatal child neglect, Child Welfare 69 (4) (1990) 309-319.

[32] E.L. Abel, Childhood homicide in Erie County, New York, Pediatrics 77 (5) (1986) 709-713.

[33] J. Nixon, J. Pearn, I. Wilkey, G. Petrie, Social class and violent child death: an analysis of fatal nonaccidental injury, murder, and fatal child neglect, Child Abuse Neglect 5 (2) (1981) 111-116.

[34] K. Bullock, N. Tilley, Shootings, Gangs and Violent Incidents in Manchester: Developing a Crime Reduction Strategy (Crime Reduction Research Series Paper 13), Home Office, London, 2002.

[35] M.D. Maltz, On defining "organized crime": the development of a definition and a typology, Crime Delinquency 22 (3) (1976) 338-346.

[36] S. Lupo, Storia della mafia: Dalle origini ai giorni nostri, Donzelli Editore, Roma, 2004.

[37] Italian National Institute of Statistics [ISTAT], Le vittime di omicidio, (2018) Retrieved from https://www.istat.it/it/files/2018/11/Report_Vittime-omicidi. pdf.

[38] F.N. Moro, S. Sberna, Transferring violence? Mafia killings in nontraditional areas: evidence from Italy, J. Conflict Resol. 62 (7) (2018) 1579-1601.

[39] J.A. Mercy, W.R. Hammond, Preventing homicide: a public health perspective, Studying and Preventing Homicide: Issues and Challenges, (1999), pp. 274-294.

[40] Transcrime, Progetto PON sicurezza 2007-2013: Gli investimenti delle mafie. Rapporto linea 1 Retrieved from http://www.transcrime.it/pubblicazioni/ progetto-pon-sicurezza-2007-2013/, Ministero dell'Interno, Milano, 2013.

[41] G. Minelli, V. Manno, S.M. D’Ottavi, M. Masocco, G. Rago, M. Vichi, et al., Mortality in Italy in 2006, Appendix A and Appendix B (Rapporti ISTISAN, 26), (2010). 
[42] Italian National Institute of Statistics [ISTAT], Matrimoni, Separazioni e Divorzi, (2016) Retrieved from https://www.istat.it/it/archivio/192509.

[43] M. Eisner, Long-term historical trends in violent crime, Crime Justice 30 (2003) 83-142.

[44] A. Colombo, Gli stranieri e la sicurezza, in: M. Barbagli, U. Gatti(Eds.), Rapporto Sulla Criminalità e la sicurezza in Italia 2010, il Sole 24 Ore, Roma, 2011, pp. 269-341.

[45] J. Dickie, Mafia Republic: Italy's Criminal Curse: Cosa Nostra, Camorra and 'Ndrangheta from 1946 to the Present, Sceptre, London, 2013.

[46] L. Paoli, Mafia Brotherhoods: Organized Crime, Italian Style pp. 54-55, 60-61, 88, Oxford University Press, New York, NY, 2003.

[47] M. Galeotti, Gangster's paradise: how organized crime took over Russia, The Guardian, (2018) Retrieved from https://www.theguardian.com/news/2018/ mar/23/how-organised-crime-took-over-russia-vory-super-mafia.

[48] A. Utrata, C. Schiciano, J. Becker, Russian organized crime, Stanford Model United Nations Conference 2014 (2014).

[49] M.F. Aebi, Crime trends in Western Europe from 1990 to 2000, Eur. J. Criminal Policy Res. 10 (2-3) (2004) 163-186.

[50] H.C. Chan, K.M. Heide, Weapons used by juveniles and adult offenders in sexual homicides: an empirical analysis of 29 years of US data, J. Invest. Psychol. Offender Profiling 5 (3) (2008) 189-208.

[51] H.C. Chan, K.M. Heide, E. Beauregard, Male and female single-victim sexual homicide offenders: distinguishing the types of weapons used in killing their victims, Sexual Abuse 31 (2) (2019) 127-150.
[52] M. Rying, Dödligt våld mot barn - mindre nu än förr [lethal violence against children-Less now than before], Välfärd 4 (2004) 18-19.

[53] L. Somander, L. Rammer, Intra- and extrafamilial child homicides in Sweden 1971-1980, Child Abuse Neglect 15 (1-2) (1991) 45-55.

[54] P. Roma, P. Pazzelli, M. Pompili, D. Lester, P. Girardi, S. Ferracuti, Mental illness in homicide-suicide: a review, J. Am. Acad. Psychiatry Law 40 (4) (2012) 462 468.

[55] P. Roma, A. Spacca, M. Pompili, D. Lester, R. Tatarelli, P. Girardi, S. Ferracuti, The epidemiology of homicide-suicide in Italy: a newspaper study from 1985 to 2008, Forensic Sci. Int. 214 (1-3) (2012) 1-5, doi:http://dx.doi.org/10.1016/j. forsciint.2011.06.022.

[56] P. Roma, M. Pompili, D. Lester, F. Ferracuti, Incremental condition of isolation as predictor of suicide of prisoners, Forensic Sci. Int. 233 (2013) 1-3.

[57] N. Elias, Il processo di civilizzazione, Il Mulino (ed. or. Über den Prozess des Zivilisation. I. Wandlungen des Verhaltens in den Weltlichen Oberschichten des Abendlandes; II), Bologna, 1988.

[58] M. Eisner, M. Killias, Country survey: Switzerland, Eur. J. Criminol. 1 (2004) 257-293.

[59] A.R. Harris, S.H. Thomas, G.A. Fisher, D.J. Hirsch, Murder and medicine. The lethality of criminal assault 1960-1999, Homicide Stud. 6 (2) (2002) 128-166.

[60] G. Palumbo, F. Mirabella, A. Gigantesco, Positive screening and risk factors for post-partum depression, Eur. Psychiatry 42 (2017) 77-85. 